\title{
Evaluation of Cadmium, Arsenic, Mercury, Lead, Nickel and Speciated Organometallic Compounds in Tilapia guineensis, Sarotherodon melanotheron and Mullet (Liza falcipinnis) Found in Buguma River, Rivers State, Nigeria
}

\author{
Owhonda N. Kingsley* \\ Department of Pure and Industrial Chemistry, University of Port Harcourt, Nigeria
}

*Corresponding Author: Owhonda N. Kingsley, Department of Pure and Industrial Chemistry, University of Port Harcourt, Nigeria, E-mail: kingsleyndubuisiowhonda@gmail.com

Received: 30 June 2017; Accepted: 07 July 2017; Published: 17 July 2017

\begin{abstract}
The edible flesh of guinean tilapia (Tilapia guineensis), blackchin tilapia (Sarotherondon melanotheron) and mullet (Liza falcipinnis) were collected from Buguma River for elemental studies of cadmium, mercury, arsenic, lead, nickel and organometallic forms of elements using X-ray fluorescence (XRF) and Gas chromatography-mass spectrometer (GC-MS) respectively. The highest concentration of cadmium $(1.7 \mathrm{mg} / \mathrm{kg})$ was observed in Tilapia guineensis. They all contained about the same concentration of arsenic $(0.5 \mathrm{mg} / \mathrm{kg})$ and mercury $(1 \mathrm{mg} / \mathrm{kg})$. The highest concentration of lead was detected in Sarotherodon melanotheron $(4.8 \mathrm{mg} / \mathrm{kg})$ while the highest concentration of nickel $(21.4 \mathrm{mg} / \mathrm{kg})$ was detected in Tilapia guineensis. The organometallic compounds detected were diethoxydimethylsilane, dimethylisobutoxysilane, diethyl(trans-4-methylcyclohexyloxy) undecycloxysilane, diethyl(decycloxy)borane, [(3a)-pregn-5-ene-3,20-diyl]bis(oxy)bis[trimethyl]silane, dimethyl(4methoxyphenoxy)dodecycloxysilane, Bis(diethylcarbamodithioato-S,S'-(T-4)zinc in Tilapia guineensis. Diethyldecycloxypentadecycloxysilane, diethoxydimethylsilane, diethyl(decycloxy)borane, dimethyl(2naphthoxy)hexadecycloxysilane in Sarotherodon melanotheron and tetracarbonylnickel, carbonylborane, trimethylaluminum, dimethoxydimethylsilane, diethyl(decycloxy)borane, pthalocyaninedichloridegermanium in mullet.
\end{abstract}

Keywords: Cadmium; Arsenic; Mercury; Lead; Nickel; Organometallic compound; Tilapia guineensis (guinean tilapia); Sarotherodon melanotheron (blackchin tilapia); Mullet (Liza falcipinnis; X-ray fluorescence; GC-MS 


\section{Introduction}

Cadmium, arsenic, lead and mercury are noted to have caused major human health problems all over the world [1]. Cadmium inhibits membrane-bound enzymes [2]. This happens because at high concentrations cadmium forms a complex with sulphydryl groups in the active sites of enzymes which interfere with the formation of enzymesubstrate complex [3]. Cleland [4] suggested that treating cadmium toxicity with dithiothreitol (DTT) is better since it serves as a chelator and also restores sulphydryl groups. The largest source of arsenic as well as other metals is food. Specific examples of such food are seafood, poultry, rice and mushrooms [5-8].

Mercury has the ability to form methylmercury $(\mathrm{MeHg}$ ) through microbe bio-transformation in fishes. Sometimes the accumulated form is several thousand times higher than the surrounding water [9]. Methylmercury is toxic and can easily be accumulated in the food chain [10]. Fish is a source of food for humans thus, methylmercury can be ingested through fish consumption. In the human body, methylmercury targets liver, kidney, the nervous system and prenatal life for its toxic effects [11]. It is reported that high lead concentration reduces aquatic population example, mussel [12]. It is also suggested that potato peel should be removed before consumption and that the quantity of leafy vegetables consumed per day should be reduced since they are much more prone to heavy metal accumulation [13]. It has been said that nickel toxicity effect in animals among others includes retarded growth and development [14]. WHO [15] has warned that many elements exists in different forms. Some forms are toxic while others are not. This work was carried out to evaluate these elements and the organometallic forms present in these three fish species from Buguma River, Asaritoru Local Government Area, Rivers State, Nigeria.

\section{Materials and Method}

\subsection{Study area}

With a population of over 135, 000, Buguma is located 4.74 latitude and 6.86 longitude (See the arrow in Figure 1 below). Buguma has an elevation of 378 meters above sea level. Buguma river is brackish with salinity fluctuation of between 5 to over $20 \mathrm{ppt}$ throughout the year.

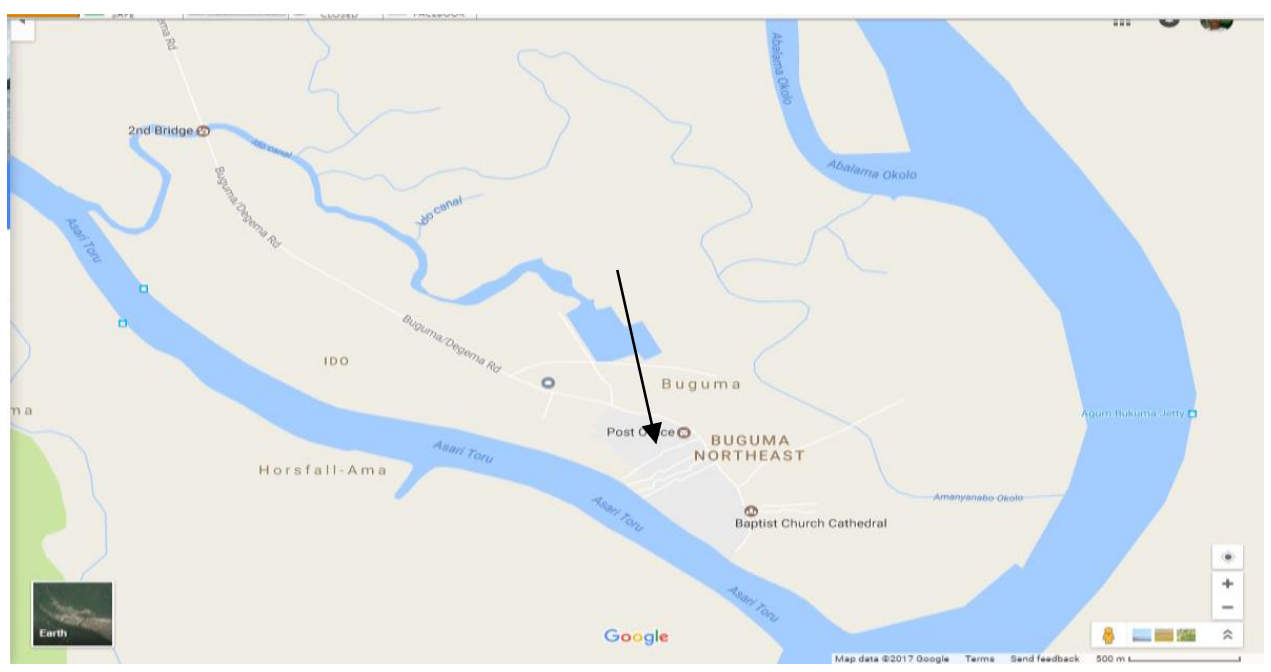

Figure 1: Location of Buguma. 


\subsection{Sampling and sample preparation for $\mathbf{x}$-ray fluorescence}

The fresh samples of Tilapia guineensis and Sarotherdon melanotheron and mullet (Liza falcipinnis) were collected from Buguma River (See Figures 2, 3 and 4). Some table size of each fish species were collected, cleaned, wrapped in aluminum foil and put into ice. The entire content was put in a black polyethylene bag and carried in a cooler for analyses.

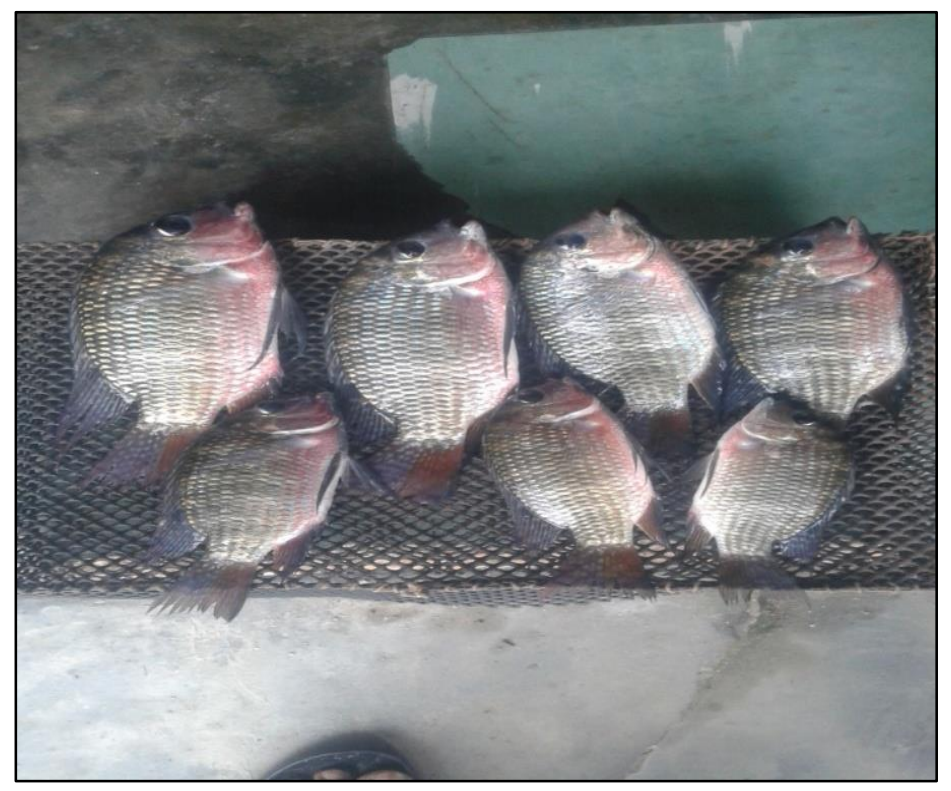

Figure 2: Tilapia guineensis.

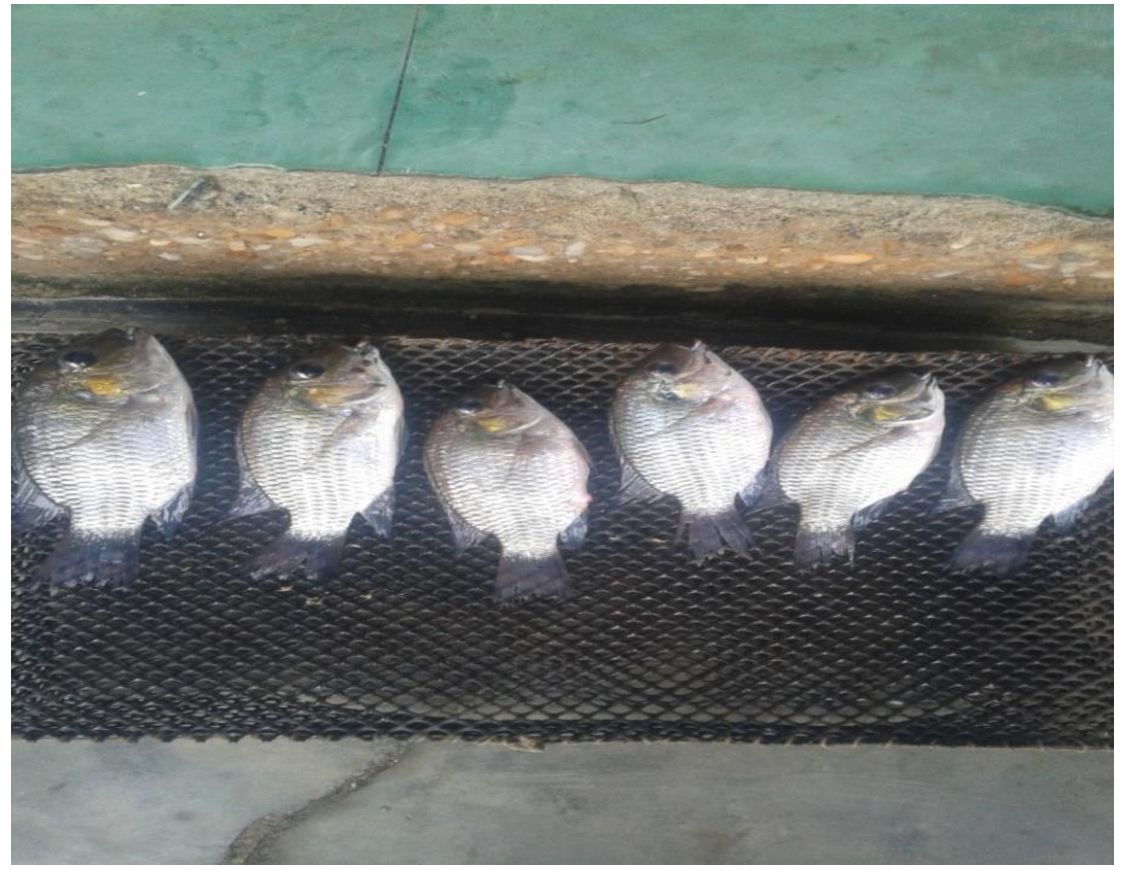

Figure 3: Sarotherodon melanotheron. 


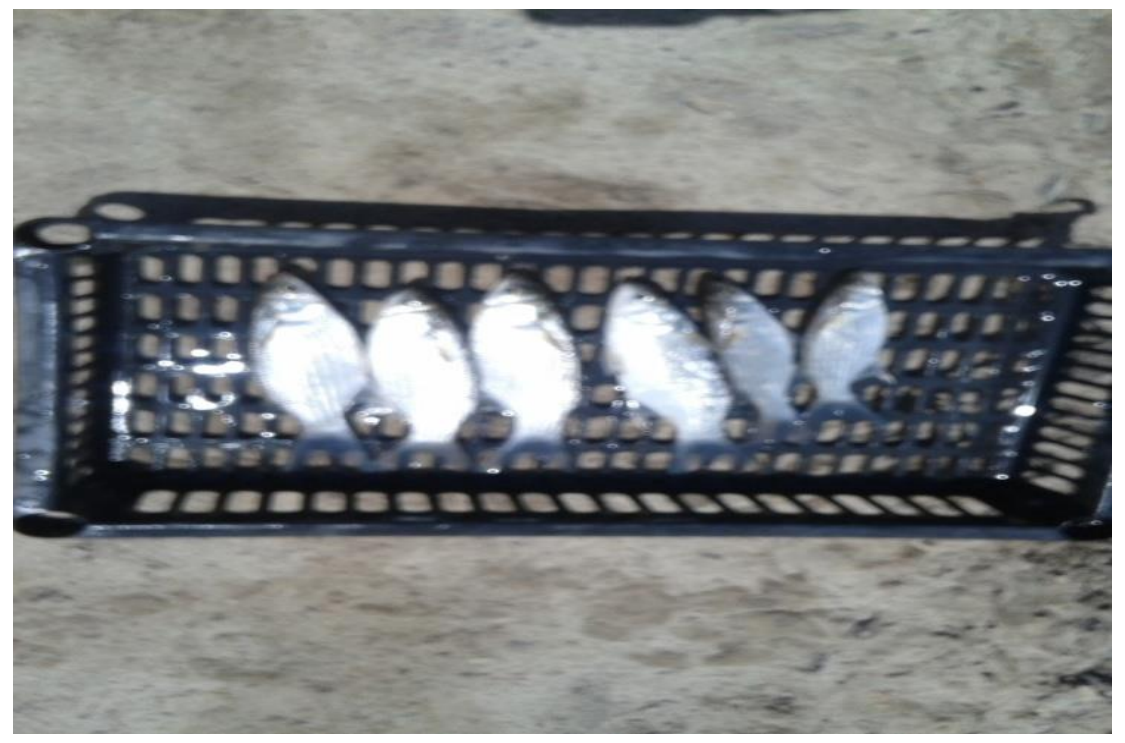

Figure 4: Mullet (Liza falcipinnis).

\subsection{Sample analysis and quality control for $x$-ray fluorescence}

The sample analysis with X-ray fluorescence was carried out at Fugro Nigeria Limited, Port Harcourt. The concentrations of cadmium, arsenic, mercury, lead and nickel were determined using X-ray fluorescence spectrometer in accordance with USEPA 6200. Fish samples were oven dried at $110^{\circ} \mathrm{C}$ for twenty hours. With the unwanted material like bones of fish etc. removed, the fleshy part of the sample was reduced to less than $2 \mu \mathrm{m}$ diameter by crushing. Crushed samples were further pulverized (i.e. crushed until it becomes powder). They were then processed into pressed pellets, transferred to clean prolene foil and then into a sample vial, labelled, arranged in the sample tray and finally transferred to the sample compartment of the X-ray fluorescence equipment (SpectroXLabPro) and then screened for their elemental composition. The concentration of each element was obtained via a previously stored calibration with certified reference materials. Results were calculated automatically as the necessary sample details were computed in the software. The XRF excitation source was X-ray tube (synchrotron). Matrix effect was corrected by grinding grain size to $25 \mu \mathrm{m}$, applying same standard used for calibration to run the sample and using mathematical modelTurboQuant (Lucas tooth) for calibration. The sample was analyzed multiple times to check reproducibility. The mean, standard deviation and mean errors were calculated automatically by the software. The five filters used for the analysis were Bragg crystal (HOPG), Compton/secondary (Molybdenum), Barkla Scatter (aluminum), Compton/secondary (palladium) and secondary target (K) (cobalt).

\subsection{Sampling and sample preparation for GC-MS analysis}

Two steps were involved in the GC-MS analysis. The first stage involved extraction while the second involved derivatization before the final chromatographing.

In accordance with IUPAC [16], the scales were removed from fish with ceramic knife. The edible part was then cut with ceramic knife and then homogenized with mortar and pistol. Two grams of fish was collected. Then, $5 \mathrm{ml}$ of $20 \%$ tetramethyl ammonia hydroxide (TMAH) was added to digest the fish which was immediately transferred to water bath at $60^{\circ} \mathrm{C}$ for 2 hours. After 2 hours, the $\mathrm{pH}$ was checked to ensure it is between 6-8. Small quantities of 
hydrochloric acid $(\mathrm{HCl})$ were added to ensure the $\mathrm{pH}$ was within the required range. Then, $3 \mathrm{ml}$ of $0.5 \mathrm{M}$ sodium diethyldithiocarbamate (NaDDTC) was added. Afterwards, equal amounts of $1.5 \mathrm{ml}$ of toluene and $1.5 \mathrm{ml}$ of benzene were added. It was then agitated for 2 hours in a mechanical shaker.

In the second stage $5 \mathrm{ml}$ of the sample prepared from step 1 was collected with the help of the syringe. A large balloon was filled with nitrogen. Then the air in the sample from step 1 was flushed with the nitrogen in the balloon for some minutes. With the flushing still on, $3 \mathrm{ml}$ of $\mathrm{n}$-Buthylmagnesium chloride $(\mathrm{n}-\mathrm{BuMgCl})$ and $2 \mathrm{ml}$ tetrahydrofuran (THF) was added and then agitated for 10 minutes. Afterwards, $10 \mathrm{ml}$ of $0.5 \mathrm{M} \mathrm{H}_{2} \mathrm{SO}_{4}$ was added to destroy excess Grignard reagent. Then the two phases that was produced were separated. The organic phase (i.e. milky part) was sent for GC-MS analysis.

\section{Results and Discussion}

\subsection{Results}

3.1.1 X-ray fluorescence: Table 1 shows the concentrations of cadmium, arsenic, mercury, lead and nickel in the three fish species while Figure 5 compares the elements.

\begin{tabular}{|l|l|l|l|l|l|}
\hline Fish Specie & $\begin{array}{l}\text { Cadmium } \\
(\mathbf{m g} / \mathbf{k g})\end{array}$ & $\begin{array}{l}\text { Arsenic } \\
(\mathbf{m g} / \mathbf{k g})\end{array}$ & $\begin{array}{l}\text { Mercury } \\
(\mathbf{m g} / \mathbf{k g})\end{array}$ & $\begin{array}{l}\text { Lead } \\
(\mathbf{m g} / \mathbf{k g})\end{array}$ & $\begin{array}{l}\text { Nickel } \\
(\mathbf{m g} / \mathbf{k g})\end{array}$ \\
\hline Tilapia guineensis & 1.7 & 0.5 & 1.0 & 1.9 & 21.4 \\
\hline Sarotherodon melanotheron & 1.1 & 0.5 & 1.0 & 4.8 & 19.7 \\
\hline Mullet (Liza falcipinnis) & 0.4 & 0.5 & 1.0 & 1.7 & 6.7 \\
\hline
\end{tabular}

Table 1: X-ray fluorescence analysis result.

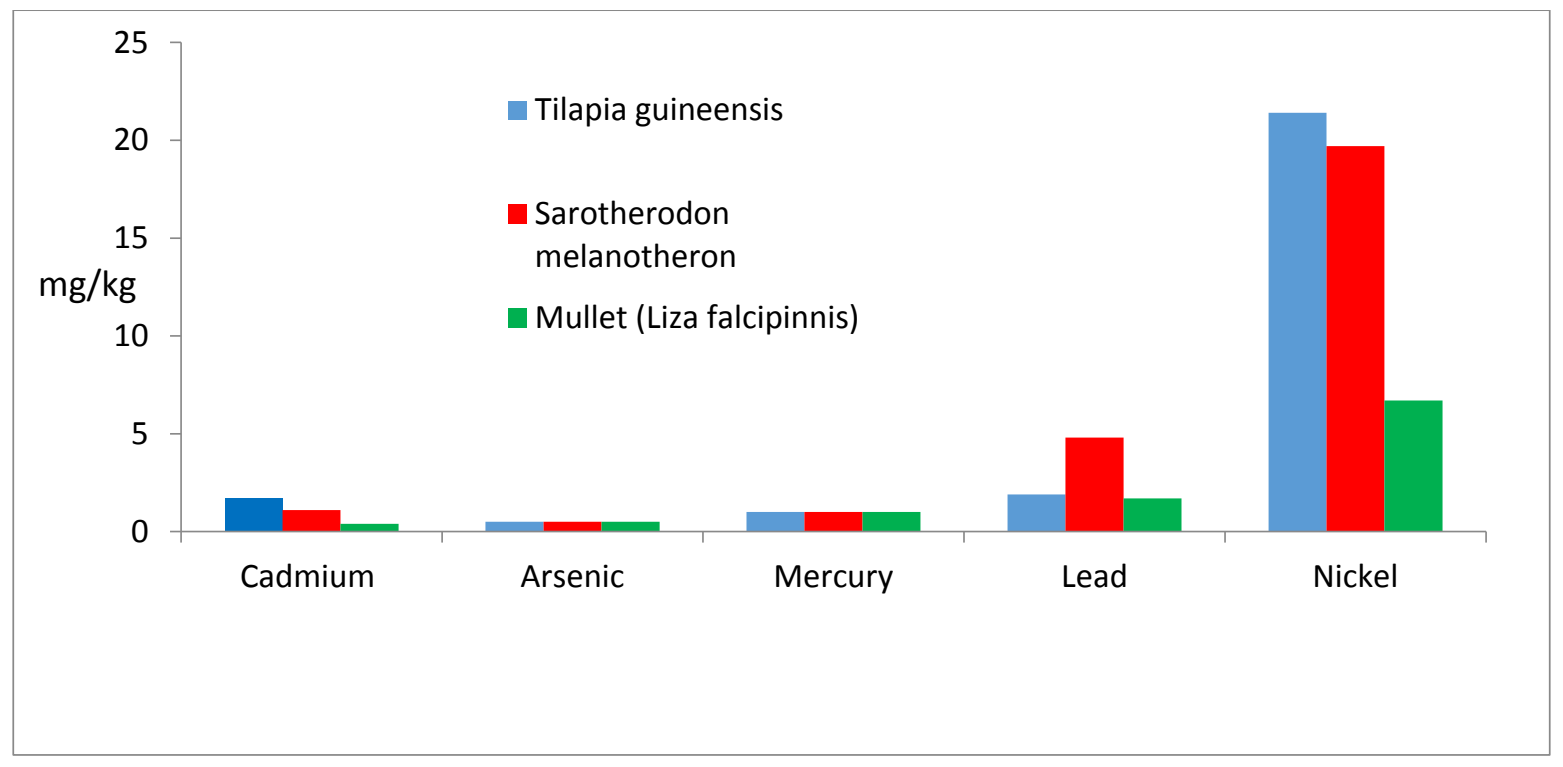

Figure 5: Concentration (in $\mathrm{mg} / \mathrm{kg}$ ) of cadmium, arsenic, mercury, lead and nickel in the three fish species. 
3.1.2 Chromatogram of GC-MS analysis

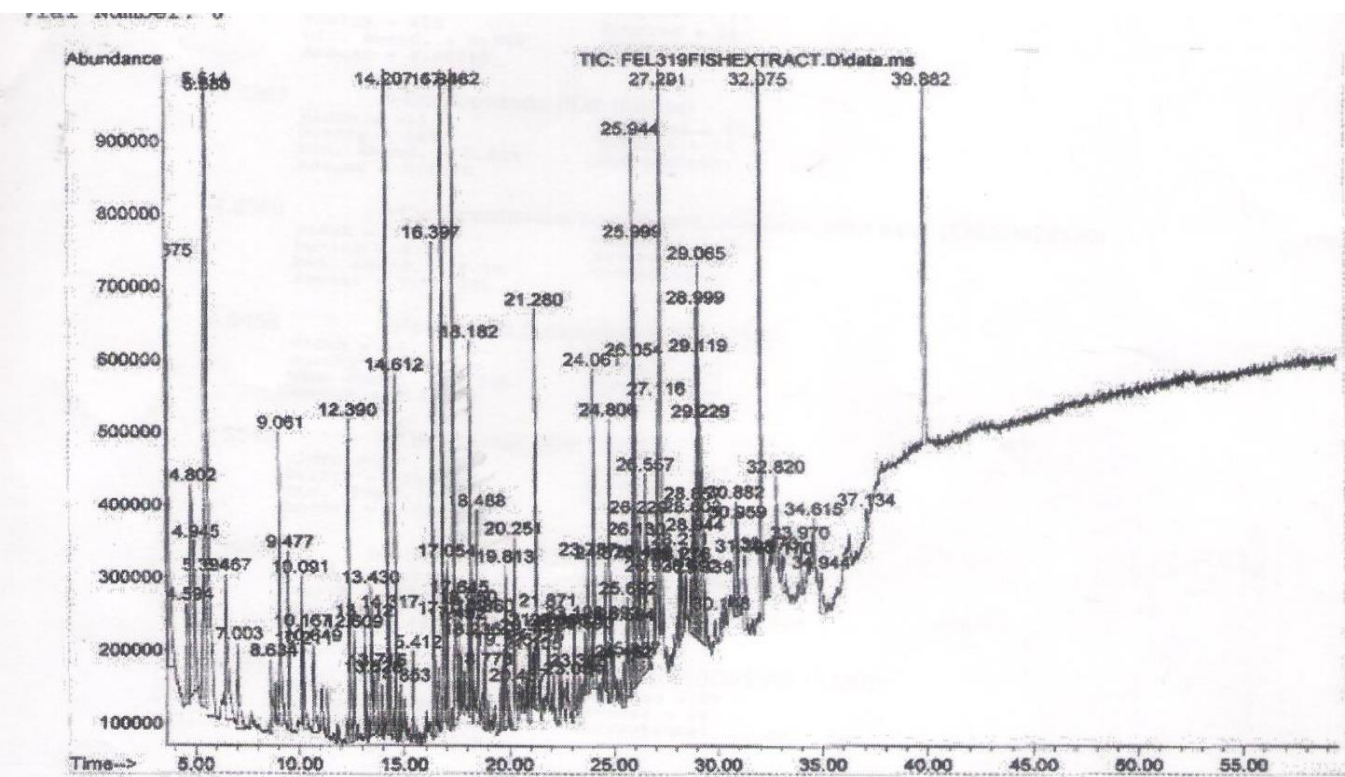

Figure 6: Chromatogram of Tilapia guineensis from Buguma River.

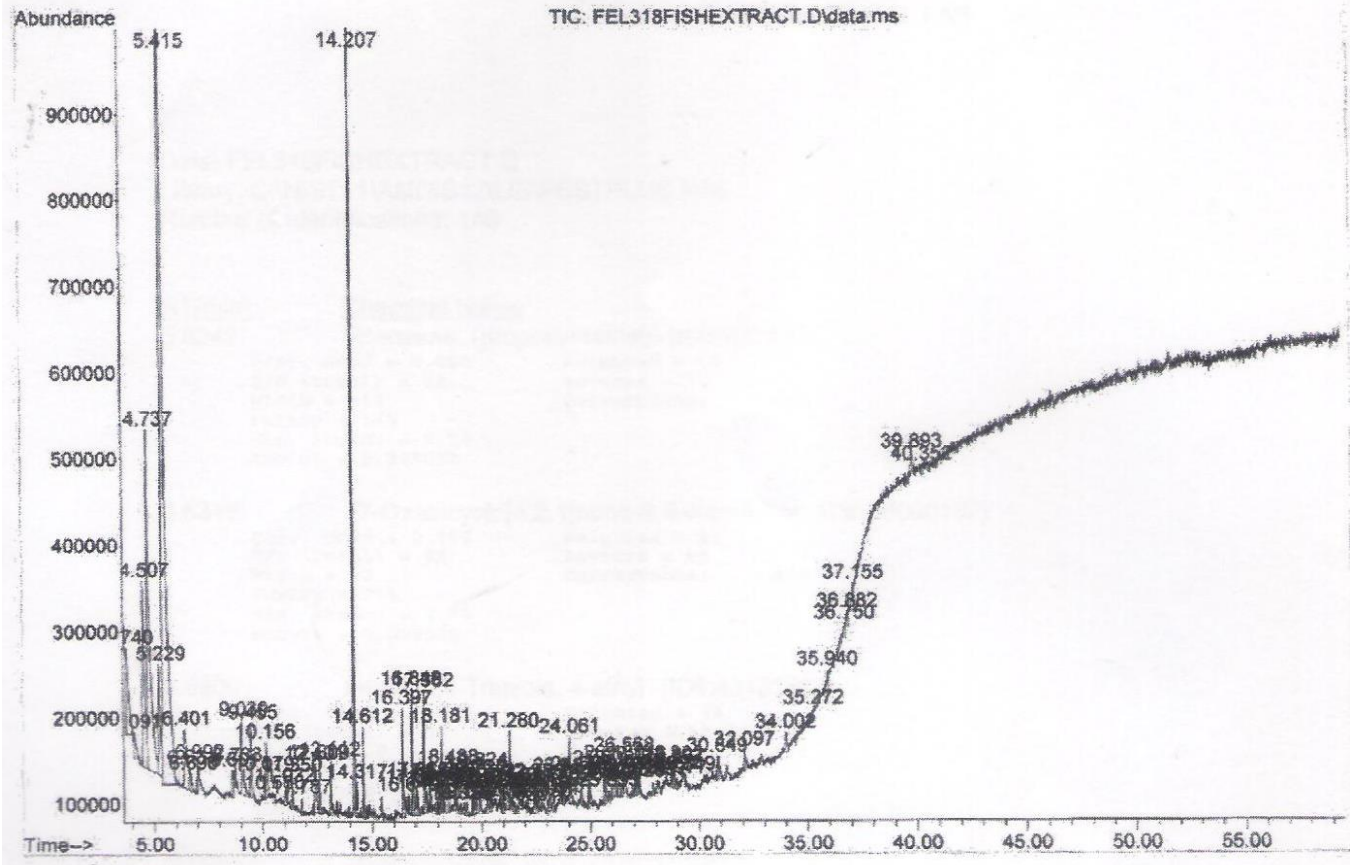

Figure 7: Chromatogram of Sarotherodon melanotheron from Buguma River. 


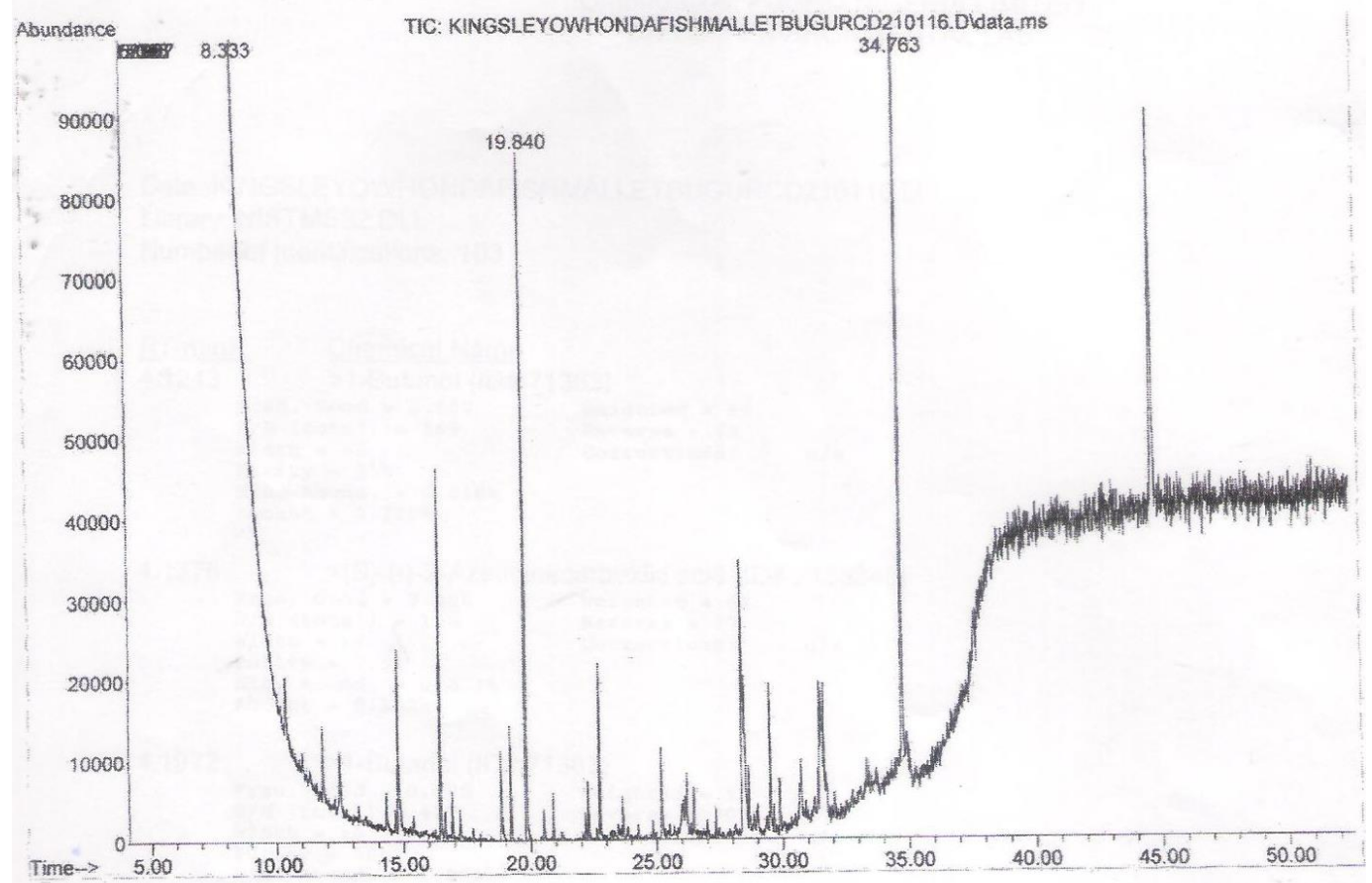

Figure 8: Chromatogram of Mullet (Liza falcipinnis) from Buguma River.

\begin{tabular}{|c|c|c|c|}
\hline Type of fish & Compound detected & $\begin{array}{l}\text { Retention time } \\
\text { (minutes) }\end{array}$ & $\begin{array}{c}\text { Amount } \\
(\%)\end{array}$ \\
\hline \multirow[t]{7}{*}{ Tilapia guineensis } & Diethoxydimethylsilane & 6.46 & $6.13 \times 10^{-2}$ \\
\hline & Dimethylisobutoxybutoxysilane & 11.04 & $7.56 \times 10^{-3}$ \\
\hline & $\begin{array}{l}\text { Diethyl(trans-4- } \\
\text { methylcyclohexyloxy)undecycloxysilane }\end{array}$ & 12.16 & $3.45 \times 10^{-4}$ \\
\hline & Diethyl(decycloxy)borane & 15.7 & $3.85 \times 10^{-4}$ \\
\hline & $\begin{array}{l}\text { [(3a)-pregn-5-ene-3,20- } \\
\text { diyl]bis(oxy)bis[trimethyl]silane }\end{array}$ & 24.31 & $3.70 \times 10^{-5}$ \\
\hline & Bis(diethylcarbamodithioato-S,S'-(T-4)zinc & 27.29 & $2.79 \times 10^{-2}$ \\
\hline & Dimethyl(4-methoxyphenoxy)dodecycloxysilane & 33.83 & $1.48 \times 10^{-4}$ \\
\hline \multirow{2}{*}{$\begin{array}{l}\text { Sarotherodon } \\
\text { melanotheron }\end{array}$} & Diethyldecycloxypentadecycloxysilane & 44.69 & $1.08 \times 10^{-3}$ \\
\hline & Diethoxydimethylsilane & 6.41 & $3.95 \times 10^{-2}$ \\
\hline
\end{tabular}




\begin{tabular}{|l|l|l|l|}
\hline \multirow{4}{*}{$\begin{array}{l}\text { Mullet } \\
\text { (Liza falcipinnis) }\end{array}$} & Dimethylisobutoxybutoxysilane & 11.34 & $7.91 \times 10^{-3}$ \\
\cline { 2 - 4 } & Diethyl(decycloxy)borane & 24.97 & $2.86 \times 10^{-3}$ \\
\cline { 2 - 4 } & Dimethyl(2-naphthoxy)hexadecycloxysilane & 39.90 & $2.84 \times 10^{-3}$ \\
\cline { 2 - 4 } & Tetracarbonylnickel & 4.22 & $8.27 \times 10^{-1}$ \\
\cline { 2 - 4 } & Carbonylborane & 5.68 & $4.20 \times 10^{-4}$ \\
\cline { 2 - 4 } & Trimethylaluminum & 8.10 & $8.02 \times 10^{-4}$ \\
\cline { 2 - 4 } & Dimethoxydimethylsilane & 14.69 & $3.49 \times 10^{-4}$ \\
\cline { 2 - 4 } & Diethyl(decycloxy)borane & 26.12 & $1.88 \times 10^{-4}$ \\
\cline { 2 - 4 } & Pthalocyaninedichloridegermanium & 44.70 & $1.44 \times 10^{-2}$ \\
\hline
\end{tabular}

Table 2: Organometallic compounds detected in the three fish species.

\subsection{Discussion}

3.2.1 Cadmium: The concentration of cadmium in the edible flesh that was detected ranged between 0.4-1.7 $\mathrm{mg} / \mathrm{kg}$ for the three fish species (See Table 1). The International Programme on Chemical Safety [17] has stated that cadmium exerts toxic effect on kidney, the skeletal system, the respiratory system and has also classified it as a carcinogen. It is readily accumulated in many organism especially, molluscs and crustaceans while lower concentrations are found in vegetables, cereals and starchy roots [18]. It recommends that the maximum safe amount of cadmium per month is $25 \mu \mathrm{g} / \mathrm{kg}$ body weight. This means that an adult weighing $60 \mathrm{~kg}$ should not take more than $1.5 \mathrm{mg}$ of cadmium per month or $0.05 \mathrm{mg}$ per day. This means that one weighing $65 \mathrm{~kg}$ should not consume more than $1.63 \mathrm{mg}$ of cadmium per month. From Table 1 this is less than the concentration of cadmium in one kilogram of fish. Thus, suggesting that consumption of upto one kilogram of these fish species per month may be harmful. One may argue also that since the cadmium in the fishes are consumed in their complexed form it is safe. On the other hand, it may also be argued that consumption of other substances such as drugs etc. may lead to the release of cadmium from the consumed fish. However, one thing stands out in this finding and it is that there is the need for moderate consumption of these fish species from Buguma river where total abstinence is not possible.

3.2.2 Arsenic: The concentration of arsenic in the edible flesh of these three fish species was $0.5 \mathrm{mg} / \mathrm{kg}$ for all the three fish species. Although this concentration appears low there is no known tolerable limit for arsenic in food $[19,20]$. Therefore, moderation in the quantity of these fish species from this river that is consumed per day may be important.

3.2.3 Mercury: The concentration of mercury in the three fish species was $1.0 \mathrm{mg} / \mathrm{kg}$. Methylmercury was not detected. WHO [21] makes it clear that mercury in any form is toxic to human health and more particularly so to the developing child in the uterus and early life. This is because mercury damages the brain, kidney and lungs. The European Union Commission Committee [22] recommends 0.5-1 mg/kg of mercury. 
3.2.4 Lead: The range of concentration of lead detected in the edible flesh of these three fish species is 1.7-4.8 $\mathrm{mg} / \mathrm{kg}$. Since there is no known level of lead exposure that is considered safe it may be important to abstain or moderate the quantity of these fish species consumed per day from this river.

3.2.5 Nickel: The concentration of nickel detected in the edible flesh of these three fish species was 6.7-21.4 $\mathrm{mg} / \mathrm{kg}$. It is estimated that humans need $5-50 \mu \mathrm{g}$ of nickel per day and that $4.2 \mu \mathrm{g}$ of nickel per kilogram body weight per day come from food [23]. Racchelle [24] however, gives an upper limit of $1 \mathrm{mg}$ of nickel per day for adults from all sources. The recommendation of Racchelle also suggests that moderation may also be required in the consumption of these fish species from this river.

The organometallic compounds detected are shown in Table 2. Nickel tetracarbonyl is the principal carbonyl compound of nickel. It is an known to be an extremely poisonous pale-yellow liquid. According to the Board on Environmental Studies and toxicology [25] it is fatal when absorbed through the skin or when inhaled due to its high volatility. It also stated that its $\mathrm{LD}_{50}$ concentration is $3 \mathrm{ppm}$. However, for humans the fatal dose is $30 \mathrm{ppm}$. This is because the half-life of nickel tetracarbonyl is just 40 seconds and so, decomposes quickly in air [26]. Due to its low concentration and short half life it may not be expected to cause harm when ingested through fish consumption.

\section{Conclusion}

Although the fish species studied contain cadmium, arsenic, mercury, lead and nickel, the result suggests that the extent of toxicity depends on the quantity of any of these three fish species consumed daily. On the other hand, the presence of some elements without tolerable limits suggests that other fish sources may be required.

\section{Acknowledgement}

Special thanks to Fugro Nigeria Limited for the analysis of the many fish samples.

\section{References}

1. Hutton M. Human Health Concerns of lead, mercury, cadmium and arsenic. Lead, mercury, cadmium and arsenic in the environment. Published by John Wiley and Sons Limited. Edited by Hutchinson and Meena (1987): 55-68.

2. Toury, R., Stelly, N., Boissonneau, E. and Dupuis, Y. Degenerate processes in skeletal muscle of Cdtreated rats and CdZf inhibition of mitochondrial $\mathrm{Ca}^{2+}$ transport. The Journal of toxicology and applied pharmacology 77 (1985): 19-35.

3. Vallee B, Ulmer D. Biochemical effects of mercury, cadmium and lead. Annual Review of Biochemistry, 41 (1972): 91-128.

4. Cleland WW. Dithiothreitol, a new protective reagent for SH groups. Biochemistry 3 (1964): 480-482.

5. Jones FT. A broad view of arsenic. Poultry Science 86 (2007): 2-14.

6. Petroczi A, Naughton DP. Mercury, cadmium and lead contamination in seafood: A comparative study to evaluate the usefulness of Target Hazard Quotients. Food Chemistry and Toxicology 47 (2009): 298-302. 
7. Nepuscz T, Petroczi A, Naughton DP. Food alert patterns for metal contamination analyses in seafoods: Longitudinal and geographical perspectives. Environment International 35 (2009): 1030-1033.

8. Smedley PL, Kinniburgh DG. A review of the source, behaviour and distribution of arsenic in natural waters. Applied Geochemistry 17 (2002): 517-568.

9. Osman A, Wuertz S, Mekkawy I, et al. The Journal of Environmental Toxicology 22 (2007): 375-389.

10. Boudou A, Ribeyre F. Mercury in the food web. Accumulation and transfer mechanisms. Metal ions in Biological Systems 34 (1997): 289-319.

11. Clarkson TW. Methylmercury. Fundamental and Applied Toxicology 16 (1990): 20-21.

12. Ning WY, Christopher G, Christopher DI, et al. Sensitivity of early life stages of freshwater mussles (Uniondae) to acute and chronic toxicity of lead, cadmium and zinc in water. The Journal of Environmental Toxicology and Chemistry 29 (2010): 2053-2063.

13. Yuangen Y, Feili L, Xiangyang B, et al. Lead, zinc and cadmium in vegetable/crops in a Zinc Smelting Region and its Potential Human Toxicity. Bulletin of Environmental Contamination and Toxicology 87 (2011): 586-590.

14. Abelardo AS, Jose LD, Jorge H. Nickel toxicity in embryos and larvae of the South American toad. Effects on cell differentiation, morphogenesis and oxygen consumption. The Journal of Environmental toxicology and Chemistry 30 (2011):1146-1152.

15. WHO. Arsenic and Arsenic Compounds (Environmental Health Criteria 224), 2nd ed. Geneva: World Health Organization, International Programme on Chemical Safety (2001): 1- 8.

16. International Union of Pure and Applied Chemistry (IUPAC). Speciation of lead in Environmental and Biological samples. Pure and Applied Chemistry 67 (1995): 615-648.

17. International Programme on Chemical Safety. Cadmium, cadmium chloride, cadmium oxide, cadmium sulphide, cadmium acetate, cadmium sulphate. Geneva, World Health Organization (2007): 1075-1318.

18. WHO (World Health Organization). Preventing Disease through Healthy Environments. Exposure to Cadmium. A Major Public Health Concern. Geneva (2010): 1-3.

19. FAO/WHO. Summary and conclusions of the seventy-second meeting of the Joint FAO/WHO Expert Committee on Food Additives, Rome Food and Agriculture Organization of the United Nations; Geneva, World Health Organization (2010):1-10.

20. WHO (World Health Organization). Public Health and Environment. In: Preventing disease through healthy environments. Exposure to lead, a Major Public Concern (2010): 3-6

21. WHO (World Health Organization): Preventing disease through healthy environments. Exposure to mercury: A Major Public Concern (2007): 1-4.

22. European Union Commission Committee for regulating heavy metals Directive 2001/22/EC (2001): 1-5.

23. European Medicines Agency. Preauthorization Evaluation of Medicines for Human Use (2007): 1-32.

24. Racchelle B. Department of Medicine, University of Montreal. Lung cancer risk associated with occupational exposure to nickel, chromium (VI) and cadmium in two population-based studies in Montreal (2008): 10-15. 
25. Board on Environmental Studies and Toxicology. "Nickel Carbonyl": Acute Exposure Guideline Levels". Acute Exposure Guideline Levels for Selected Airbone Chemicals 6. National Academics Press (2008): 213-259.

26. Stedman DH, Hikade DD, Pearson R, et al. Nickel Carbonyl: Decomposition in Air and Related Kinetics Studies. Science 208 (1980): 1029-1031. 